\title{
Fibrodysplasia ossificans progressiva - A rare case
}

\author{
N. S. Dhaniwala ${ }^{1, *}$, Venkatesh Dasari ${ }^{2}$, Malhar Jadhav ${ }^{3}$, Vrushabh Kumbhare ${ }^{4}$ \\ ${ }^{1}$ Professor, ${ }^{\mathbf{2 , 3 , 4}}$ Resident, Dept. of Orthopaedic, Datta Meghe Institute of Medical Sciences, Wardha, Maharashtra, India
}

*Corresponding Author:

Email: nsdhaniwala@gmail.com

\begin{abstract}
Fibrodysplasia Ossificans Progressiva (FOP) also known as Myositis Ossificans Progressiva is a very rare and disabling genetic condition characterized by congenital malformation of the great toes with hallux valgus and progressive heterotopic ossification in specific anatomic pattern. ${ }^{1}$ It is a rare condition with worldwide prevalence of about 1 case in 2 million individuals ${ }^{2}$. No ethnic, racial, sex or geographical predisposition is noted. Myositis Ossificans Progressiva term is misnomer and not used now.

The case report herein describes this rare condition in a child of one and half year age having the classical clinical presentation and radiological features. The child is under follow- up with measures to prevent fast progression of the condition.
\end{abstract}

Keywords: Fibrodysplasia, Ossificans, Progressiva, Myositis.

The parents of an 18 months old girl presented in orthopedic out-patient department of our tertiary care hospital in the central India, with the chief complaints of swelling over neck and lower back for 8 months. The child was born at full term by normal vaginal delivery and cried immediately after birth. The baby had normal developmental milestones till one year of age. Around 8 months back she fell down from cot and developed swelling over scalp and face which subsided in a few days after treatment. Soon after, the mother noticed swelling over neck, arm and lower back with restriction of movements of neck and both shoulders. There was no history of fever, loss of weight or appetite. The child was the only issue to the young parents.

The child was thin built, $80 \mathrm{~cm}$ tall, weighing 7.5 kg., undernourished with BMI 11.72, having pulse $110 /$ minute and respiratory rate of $20 / \mathrm{mt}$. She was irritable and resisted physical examination. Systemic examination did not reveal any abnormality except bilateral smaller great toes with hallux valgus deformity (Fig. 1). Examination of skeletal system revealed firm prominence on both the sides of neck with gross limitation of all neck movements. There was long cord like hard and irregular swelling extending on inner aspect of both the arms from axilla to elbow, more extensive on right side than left. Swellings were nontender, hard on feel, free from overlying skin and the underlying bone and yet immobile. Right shoulder had no movements while left shoulder abduction was 0 to 50 degrees with absence of other movements. Spine was nontender having a scoliotic curve in dorso-lumbar area. There was cord like thickened swellings on the sides of lumbar spine extending obliquely downwards and outwards towards lumbosacral junction (Fig. 2). Spine movements were also grossly restricted.

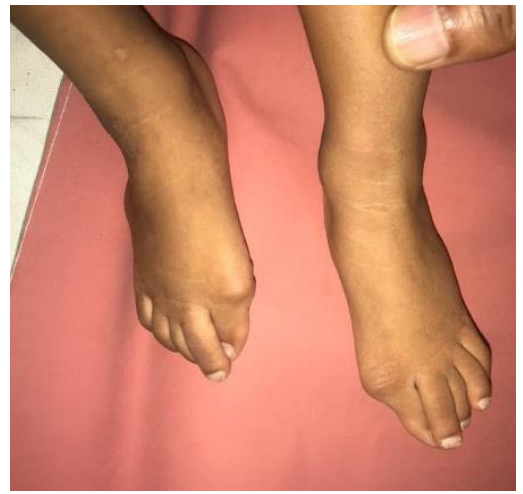

Fig. 1: Shows both feet having shorter great toe with Hallux Valgus

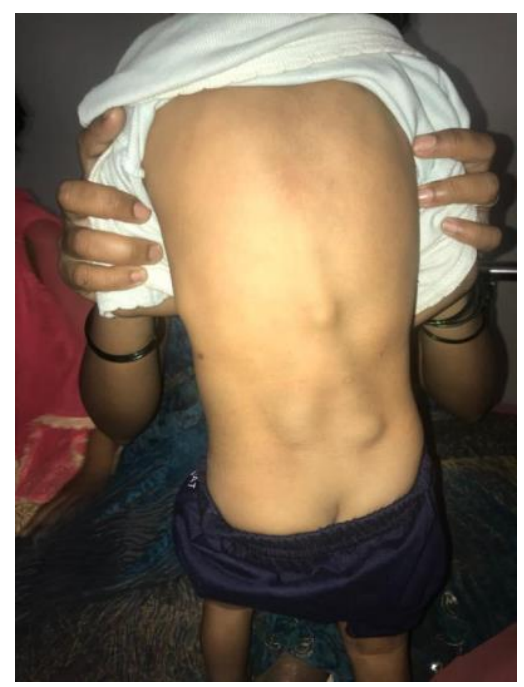

Fig. 2: Clinical Picture of back of the patient showing cord like thickening in lower back in a triangular shape, besides fullness on both sides extending from upper lumbar spine towards the lower ribs

Blood investigations were $\mathrm{Hb} 10.9 \mathrm{gm} / \mathrm{dL}$, serum protein $7.4 \mathrm{gm} \%$, albumin $4.8 \mathrm{gm} \%$, and globulin 
$2.6 \mathrm{gm} \%$. All the parameters were within normal range except serum alkaline phosphatase raised to $702 \mathrm{IU} / \mathrm{dL}$ (normal being up to 302IU). X-ray of neck showed fluffy calcification of soft tissues on both the sides of neck. Xray of shoulders showed dense calcification on inner aspects of arm extending from axilla to lower arm without involvement of humerus bone (Fig. 3). X-ray of spine showed dense calcification of paravertebral tissues in lumbar spine along with dense calcific cord extending obliquely from lumbar spine towards the rib cage (Fig. 4).

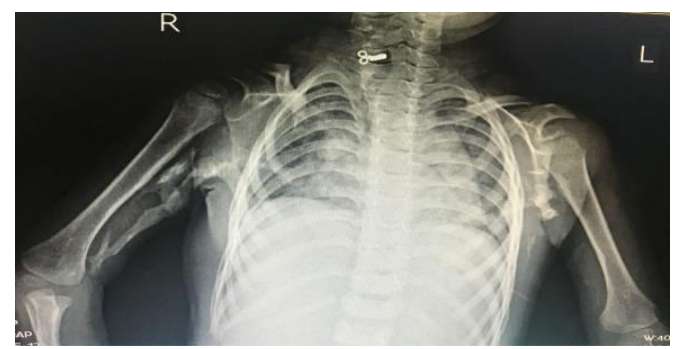

Fig. 3: Shows irregular ossification of soft tissues on medial aspect of both arms, more on right than left with mild scoliosis

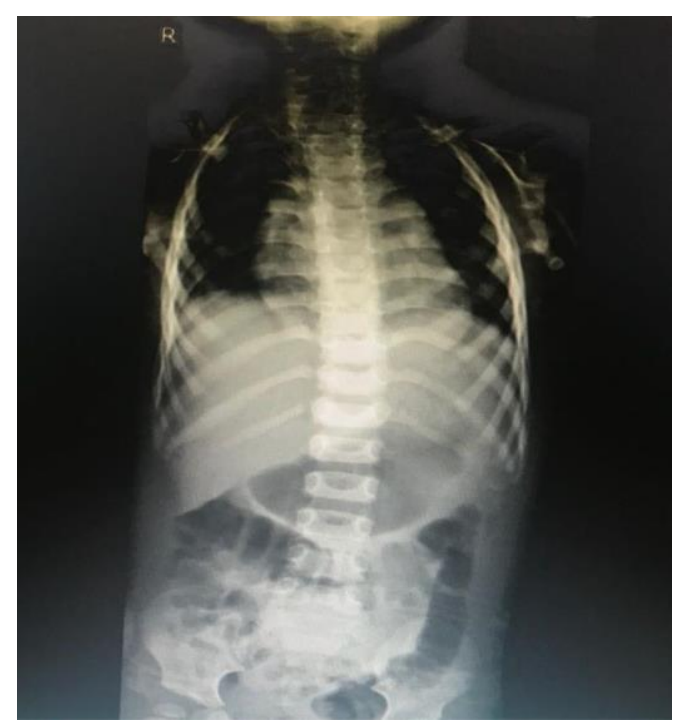

Fig. 4: Shows cord like thickening extending bilaterally from $L 3$ vertebrae towards lower ribs and irregular ossification of soft tissues in paravertebral areas

Due to absence of any effective treatment for the condition, the parents were explained the nature of disease and its likely course. A trial of bisphosphonate in the dose of $35 \mathrm{mg} /$ week was started along with vitamin c to retard the process of soft tissue calcification. Avoidance of trauma in the form of massage, falls and intra-muscular injections was also explained. The child continues to be under follow up. Her pain is less, though activities remain limited.

\section{Discussion}

Fibrodysplasia Ossificans Progressiva (FOP) occurs due to spontaneous genetic mutation and is autosomal dominant in inheritance pattern. Progressive postnatal heterotopic ossification in FOP starts in the first decade of life spontaneously or follows minor trauma. It presents as painful swellings in soft connective tissue, including ligaments, tendons, skeletal muscles and ligaments. ${ }^{2}$ Its pathology involves immune system as suggested by presence of macrophages, lymphocytes and mast cells in early lesions, flare-ups following viral fever, and beneficial response in early flare-ups to corticosteroids. The genetic cause is identified as a mutation in the specific domain of activin receptor in all persons suffering with classic Fibrodysplasia ossificans progressive. ${ }^{3,4}$ Individuals with this condition appear normal at birth except for malformations of the great toes, which are seen in all the patients. Episodic painful swellings in soft tissue develop in preteen age. ${ }^{5}$ These swellings soon mature to bone. Minor trauma of intramuscular injections, muscle fatigue, bruises, or trauma due to fall may start a flare- up leading to progressive heterotopic ossification. Gradually most of the patients lose joint mobility and ambulation and become confined to wheelchair by third decade of life. Heterotopic ossification in FOP involves typically first in the dorsal, axial, cranial and proximal regions of the body and later in the ventral, appendicular, caudal and distal regions. Diaphragm, tongue, extraocular muscles and smooth muscles including heart are spared.

Stiffness of neck may precede appearance of ossification in neck muscles. Anomalies in cervical vertebrae including fusion have been seen in many cases. ${ }^{6}$ Other congenital abnormalities include short malformed thumbs, clinodactyly, broad femur neck and osteochondroma on tibia. ${ }^{7}$ Severe weight loss due to ankylosed jaws, pneumonia and right heart failure may occur due to rigid fixed chest wall.

Progressive Osseous Heteroplasia (POH) characterized by cutaneous ossification besides soft tissue involvement, Non- Hereditary Heterotopic Ossification (NHHO) occurring following trauma to the localized site only, fibromatosis and lymphedema are common differential diagnosis. ${ }^{8}$ The correct diagnosis of FOP can be made clinically, even before radiographic evidence of heterotopic ossification is seen, if soft tissue lesions are associated with symmetrical malformations of the great toes. Biopsy in such cases can lead to rapid progression of the condition. Routine blood investigations are usually normal, though ESR and alkaline phosphatase values may be increased. Definite genetic testing for this condition is available helping in suspected cases. ${ }^{9}$ Hearing impairment may occur in $50 \%$ cases starting in childhood and progressing gradually.

There is no definite treatment available for this condition, but a 4 days course of steroids started within 24 hours of a flare-up, may help reduce inflammation and edema seen in the early stages of the disease. A 
typical dose of prednisone is $2 \mathrm{mg} / \mathrm{kg} / \mathrm{day}$, administered as a single dose for no more than 4 days. Use of bisphosphonates, NSAIDS, cox-2 inhibitors and muscle relaxants may be needed for control of progress and pain management. Surgical intervention is likely to provoke explosive and painful growth; hence even biopsy should not be done.

Rehabilitation of the affected patient is very important. Modification of activities, improvement in the household safety, use of protective headgear and use of ambulatory devices may be needed as long- term protective measures to avoid trauma. Prophylactic measures to avoid chest complications are also needed. Thoracic insufficiency syndrome leading to lifethreatening complications of pneumonia and right sided heart failure are the usual terminal events. The median age of survival is 41 years.

This condition was first described by Guypatin in 1962 on observing a young female who had become like stone. ${ }^{10}$ More than 550 cases had been described by 1982. ${ }^{11}$ In India the condition has been reported infrequently. Vijay k et al ${ }^{12}$ and Dhaniwala $\mathrm{NS}^{13}$ reported it in 1997 \& 1998 respectively. The case reported herein presented in a classical fashion following minimal trauma and involved neck, both arm and back along with chest. The movements of the involved parts were grossly restricted and child had difficulty in eating, bending forwards and normal play activities. She had the characteristic bilateral hallux valgus with smaller great toes. X-rays showed ossification in soft tissues in irregular fashion.

\section{Clinical Message}

Knowledge of Fibrodysplasia Ossificans Progressiva and its prognosis is important for an orthopedic surgeon. Though a very rare condition, it is autosomal dominant in inheritance. Physiotherapy, psychotherapy, genetic counseling, prevention and treatment of chest infections should be included in treatment besides pharmaceutical measures probably slowing down the progress of disease.

Funding: No funding sources.

Conflict of interest: None declared.

\section{References}

1. Cohen RB, Hahn GV, Tabas JA, et al. The natural history of heterotopic ossification in patients who have fibrodysplasia ossificans progressiva. A study of fortyfour patients. J Bone Joint Surg Am 1993;75(2):215-19.

2. Pignolo RJ, Shore EM, Kaplan FS. Fibrodysplasia ossificans progressiva: clinical and genetic aspects. Orphanet J Rare Dis 2011;6:80.

3. Kaplan FS, Groppe J, Pignolo RJ, Shore EM. Morphogen receptor genes and metamorphogenes: skeleton keys to metamorphosis. Ann N Y Acad Sci 2007;1116:113-33.

4. Shore EM, Xu M, Feldman GJ, et al. A recurrent mutation in the BMP type I receptor ACVR1 causes inherited and sporadic fibrodysplasia ossificans progressiva. Nat Genet 2006;38(5):525-7.

5. Rocke DM, Zasloff M, Peeper J, Cohen RB, Kaplan FS. Age- and joint-specific risk of initial heterotopic ossification in patients who have fibrodysplasia ossificans progressiva. Clin Orthop Relat Res 1994;243-48.

6. Schaffer AA, Kaplan FS, Tracy MR, et al. Developmental anomalies of the cervical spine in patients with fibrodysplasia ossificans progressiva are distinctly different from those in patients with Klippel-Feil syndrome: clues from the BMP signaling pathway. Spine (Phila Pa 1976). 2005;30(12):1379-85.

7. Deirmengian GK, Hebela NM, O'Connell M, Glaser DL, Shore EM, Kaplan FS. Proximal tibial osteochondromas in patients with fibrodysplasia ossificans progressiva. $J$ Bone Joint Surg Am 2008;90(2):366-74.

8. Kitterman JA, Kantanie S, Rocke DM, Kaplan FS. Iatrogenic harm caused by diagnostic errors in fibrodysplasia ossificans progressiva. Pediatr 2005;116(5):e654-61.

9. Kaplan FS, Xu M, Glaser DL, et al. Early diagnosis of fibrodysplasia ossificans progressiva. Pediatr 2008;121(5):e1295-300.

10. Pack, G.T. and Braund R.R. The development of sarcoma in myositis ossifican. J Am Assoc 1942:119:776

11. Connor J.M. and Evan DAP. Fibrodysplasia Ossificans Progressiva, The clinical features and natural history of 34 patients. J Bone Joint Surg 1982:64B 1:76

12. Vijay K, Sood L.K, Mandal D.K. et al. Myositis Ossificans Progressiva. Ind J Orthop 1997;31:211.

13. Dhaniwala N.S. Myositis Ossificans Progressiva. Indian Practitioner 1998;51(9):752-54.

How to cite this article: Dhaniwala N., Dasari V., Jadhav M., Kumbhare V. Fibrodysplasia ossificans progressiva A rare case. IP Int J Orthop Rheumatol 2018;4(2):73-5. 